\title{
¿Cómo se cuenta la historia a los jóvenes de Chile entero? Historia oficial y subalternidad en los textos escolares de $1^{\circ}$ y $2^{\circ}$ medio (2009-2019)
}

How is the history told to the youth of the whole of Chile? Official history and subalternity in the 1st and 2nd grade high school textbooks (2009-2019)

\author{
Paulina Arcos B. ${ }^{a}$, Cristhina González S. ${ }^{\mathrm{b}}$ \& Marcela Vargas C. \\ aUniversidad Austral de Chile, Valdivia, Chile. $₫$ paulinaarcosbarrientos@gmail.com \\ [orcid.org/0000-0002-4876-1269] \\ bUniversidad Austral de Chile, Valdivia, Chile. cristhina.gs@gmail.com \\ [orcid.org/0000-0003-1251-5143] \\ cUniversidad Austral de Chile, Valdivia, Chile. marcela.vargas@uach.cl \\ [orcid.org/0000-0002-3484-7029]
}

\section{RESUMEN}

Este artículo analiza una década de transformaciones curriculares (2009-2019) y el impacto de éstas en el relato de la historia escolar, con énfasis en las mujeres y pueblos originarios como "otros" en el relato oficial. Nos planteamos como objetivos analizar, a partir de las bases curriculares y textos escolares, la construcción de la idea del otro en la narrativa histórica propuesta en el currículum escolar entre 2010-2019 para $1^{\circ}$ y $2^{\circ}$ medio, definir el rol de la historia oficial y los estudios subalternos en la narrativa de los textos escolares de $1^{\circ}$ y $2^{\circ}$ medio, e identificar la relación entre el currículum en historia y las reformas y actualizaciones en la última década.

PALABRAS CLAVE: Historia oficial, estudios subalternos, reformas educativas, mujeres, pueblos originarios.

\section{ABSTRACT}

This article analyzes a decade of curricular transformations (2009-2019) and their impact on the narrative of school history, with an emphasis on women and indigenous peoples as "others" in the official account. Our objectives were to analyze on curricular bases and textbooks the construction of the idea of the other in the historical narrative proposed in the school curriculum between 2010-2019 for $1^{\text {st }}$ and $2^{\text {nd }}$ grade high school, define the role of official history and subaltern studies in the narrative of texts middle and high school students of $1^{\text {st }}$ and $2^{\text {nd }}$ grade, and to identify the relationship between the curriculum in history and the reforms and updates in the last decade. 
P. Arcos et al.

KEY WORDS: Official history, subaltern studies, educational reforms, women, indigenous people.

\section{INTRODUCCIÓN}

Durante las últimas décadas que devienen de la "transición a la democracia" en Chile, nos encontramos con una serie de reformas educativas que refuerzan el paradigma educativo fundado durante la dictadura cívico militar (1973-1990). Elementos como la descentralización del gasto (municipalización) y privatización de la educación, sumado a mediciones estandarizadas que fomentan la competencia y el lucro, no fueron erradicados, sino que prolongados con la Ley Orgánica Constitucional de Educación (en adelante LOCE) y la Ley General de Educación (en adelante LGE) durante los gobiernos de Concertación y derecha ${ }^{1}$. La proliferación de reformas educativas promovidas por un Estado que dejó de ser "Docente" la evidenciamos hasta la actualidad. A partir de las movilizaciones estudiantiles de 2006 y 2011 nos encontramos con una serie de transformaciones en la burocracia ministerial y en el currículum de historia, respuestas de la institucionalidad que se concretaron en narrativa de la historia escolar como herramienta en la relación enseñanza-aprendizaje. Es por ello que en el presente artículo buscamos analizar el período 2009-2019, caracterizado por transformaciones para el sistema escolar respecto al currículum, específicamente en la asignatura de Historia y el relato histórico en los textos escolares desde el Ministerio de Educación (en adelante MINEDUC) a docentes y estudiantes.

Consideramos el año 2009 como punto de partida, ya que se aplicó un cambio en el paradigma de la enseñanza, integrando términos pedagógicos actualizados y objetivos de aprendizajes que respondieron a la necesidad de una formación ciudadana y laboral de acuerdo con los nuevos desafíos políticos económicos del país posdictadura. Se readecuaron los parámetros educativos en base a nuevos proyectos pedagógicos, como la integración de objetivos y Contenidos Mínimos Obligatorios (en adelante CMO) basados en competencias, se construyó nueva infraestructura, se renovó el material de estudio y se apuntó a una nivelación pedagógica; todo esto respondió a la necesidad de una actualización profunda e innovadora con base en la equidad y la calidad, como una problemática de la historia reciente de la educación, y que es retomada por los movimientos estudiantiles y docentes, con fuerza desde 2006.

Las preguntas de esta investigación son: ¿Cómo se construye la idea del otro en la narrativa histórica propuesta en el currículum escolar entre 2010-2019 para $1^{\circ}$ y $2^{\circ}$ medio? Nos enfocamos en mujeres y pueblos originarios comprendiendo que hay un espectro de otros sujetos que tampoco aparecen transversalizados en el relato, como la infancia, el campesinado y la diversidad sexual. Asimismo, nos preguntamos por el rol de la historia oficial y los estudios subalternos en el discurso de los textos escolares de $1^{\circ}$ y $2^{\circ}$ medio, y cuál es la relación entre el currículum en historia y las reformas y actualizaciones en la última década. Para responder a estas preguntas, proponemos como hipótesis que la narrativa histórica

1 Partidos como el Partido Por la Democracia (PPD), la Democracia Cristiana (DC) en la Concertación, y Renovación Nacional (RN) y Unión Demócrata Independiente (UDI) en la derecha opositora y luego gobernante. 
en la escuela continúa perpetuando una historia oficial, de hitos y procesos, colonialista y patriarcal que invisibiliza discursivamente a los otros, superponiendo hechos y procesos sobre algunos sujetos, como mujeres y pueblos originarios. En la orientación discursiva de los textos escolares de la asignatura de Historia, los temas ligados a mujeres y pueblos originarios aparecen como anexos o cápsulas de la historia nacional, y no transversalizados en los contenidos, quedando a objeción de cada docente o proyecto educativo el trabajo de estas temáticas. Es decir, se plantea una historia sin sujetos, o de sujetos notables, en donde la construcción del otro recae en el criterio docente, pero también en las voluntades y toma de decisiones que previamente desarrollan organismos como el Consejo Nacional de Educación (en adelante CNED), fortalecidos con las reformas y ajustes a la LGE.

La metodología de trabajo se basó en revisión y análisis de fuentes primarias como las bases curriculares de 2009 y 2013, textos escolares de Historia de $1^{\circ}$ y $2^{\circ}$ medio con sus ediciones actualizadas en el marco de las reformas, prensa digital entre 2009 y 2019, decretos con fuerza de ley que sustentaron a las reformas curriculares, actas de sesiones del CNED y declaraciones públicas que se plantearon en relación con las transformaciones curriculares. Asimismo, fuentes secundarias como artículos y libros que problematizan y debaten en torno a la narrativa de historia (Illanes, 1990, 2002; Pinto \& Valdivia, 2003, 2009) y los estudios subalternos (Spivak, 2003; Rivera Cusicanqui, 2010). Además, los usos de estas categorías en el sistema educativo a través del análisis de la relación entre reformas educativas y poder (Apple, 1997; Marano, 2004; Grinberg, 2010).

Nos centramos en las bases curriculares y textos escolares de $1^{\circ}$ y $2^{\circ}$ medio por explicitar al currículum como narrativa de la historia escolar, donde además se encuentran las unidades de aprendizaje ligadas a la conformación del Estado nación, debido a la relación de este contenido con la historia oficial como categoría teórica que analizaremos en relación a los sujetos. No profundizamos en $3^{\circ}$ y $4^{\circ}$ medio debido a lo reciente de las transformaciones curriculares de electividad y porque no existen experiencias educacionales para retroalimentar esta inserción, sin embargo, consideramos esa reforma curricular como un hito más en los embates que el MINEDUC ha propiciado al relato de la historia en la escuela.

\section{La historia oficial en Chile: debates y propuestas teóricas para el estudio de la historia}

Entendemos el recorrido y construcción de la historia, desde el positivismo científico por la profesionalización hacia el siglo XIX, hasta un campo que dialoga con la narrativa y las ciencias sociales hacia el siglo XX (Iggers, 2012). Estos debates abren paso a las discusiones por la historia oficial, aquella que se funda en la construcción de los Estados como relato legitimante y hegemónico, donde el proyecto es el desarrollo de una identidad común, de nación, "una comunidad política imaginada como inherentemente limitada y soberana" (Anderson, 1993, p. 23). Esta construcción, que para Chile y otros Estados nación de América Latina se remonta a la primera mitad del siglo XIX, ha generado más debates por la complejidad de la relación nación, Estado y etnicidad, si consideramos el pasado colonial, el mestizaje y las disputas por el poder político y económico, al mismo tiempo que el protagonismo de diversos sujetos que conforman las sociedades, más allá del Estado. 
La idea de pueblo en la historia es puesta en tensión con la categoría de Patria, como una construcción de imaginarios, ceremonias y ritos que modelan "la memoria del pueblo", como la celebración de fechas de batallas desde la época independentista, siendo fortalecida por el Estado portaliano (Pinto \& Valdivia, 2009). La Patria, cargada de símbolos, sin embargo, no modela sujetos pasivos. Desde fines del siglo XIX y principios del siglo XX se desarrolla un nuevo imaginario de nación: "Esta patria, al espectáculo de estos cuerpos, deberá arrancarse las medallas, arrugar su bandera, constituyendo la mortandad de pobres un 'rubor para nuestro patriotismo"” (Illanes, 2002, p. 68).

Los símbolos son utilizados en las escuelas para fortalecer el patriotismo en niños y niñas, como relata Illanes (1990) en su recorrido por la educación en la primera mitad del siglo XX en Chile, con lo que llama la "vocación" histórica de Chile: "Para comprometer a los maestros en la tarea histórica de llevar la palabra de la Tradición al pueblo, que calmase su espíritu en la veneración de las figuras endiosadas de los próceres en los templos escolares de la República” (pp. 176-177). Esta idea se profundiza en la Unidad Popular (UP) y la construcción del "hombre nuevo" como agente de cambios, y es contrarrestada por el golpe de Estado de 1973, con la exaltación militarista de la patria y la historia de los valientes soldados. Refundación nacional a través de la justificación de la decadencia de la UP (Pinto \& Valdivia, 2006), donde las escuelas fueron el espacio de transmisión de esta historia oficial, se justificó el autoritarismo y se sentaron las bases de una ciudadanía del consumo y profundamente tradicional católica (Monsálvez, 2012). La historia como base ideológica que incorporó el pueblo al Orden NaciónEstado es la historia escolar promovida a través de un currículum que hasta el tiempo presente será objeto de transformaciones (Illanes, 1990). La construcción de la historia oficial atraviesa a la historia escolar, por lo tanto, debemos preguntarnos sobre los impactos de este relato que se transmite en el aula, que está condicionado por las reformas educativas, el rol docente, las particularidades territoriales y las disposiciones de la educación de mercado. Una promoción de la desigualdad educativa encarnada en la educación como un producto de mercado y el principio de subsidiariedad del Estado, donde las familias deciden cómo educan a sus hijos e hijas.

La historia oficial que permanece en los currículos escolares, se basa en problemáticas efectivas para una clase política privilegiada, que relata aconteceres estructurados y enmarcados en un sector de la sociedad que domina sobre una población que va perdiendo su historicidad, puesto que enseña desvinculado a la memoria popular, una historia carente de sentido, según Graciela Rubio (2013), por no hablar desde una experiencia en común para formar un futuro compartido, impidiendo de esta manera un espacio de reflexión real o como dice la autora, un desencuentro con la realidad. Asimismo, tanto la historiografía como la historia escolar permiten la "invención de las naciones", deben proyectarse en relación con los desafíos de fin de siglo, como la globalización y la avanzada del neoliberalismo, que tensionan la unidad política “Estado-nación” (Carretero \& Kriger, 2004, p. 14).

\section{Subalternidad y construcción del "otro" en la historia: mujeres y pueblos originarios}

Queremos situar las categorías de subalternidad y construcción del otro con énfasis en el género y la etnia, sin desconocer la existencia de otras subalternidades como la tercera, los 
sujetos con discapacidad, considerando en primer lugar los análisis sobre alteridad desde Michel de Certeau y la escritura de la historia como antecedente, las reflexiones de Enrique Dussel. Por un lado, Dussel trabaja con la "metafísica de la alteridad", considerando la otredad latinoamericana y subdesarrollada, la otredad del tercer mundo (Bautista, 2014). Una otredad que, por otro lado, es analizada por Michel de Certeau y la necesidad de la historia como campo de estudio que se despliega para comprender lo que no ha comprendido, o lo ausente, y las complejidades para enfrentar esas escrituras sobre el "otro" sin caer en jerarquizaciones, por ejemplo, a través de las relativizaciones discursivas o la razón científica, que "está indisolublemente unida a la realidad que encuentra a su sombra y a su otro en el momento en que los excluye" (De Certeau, 2006, p. 56). En relación con este mismo hecho, De Certeau plantea la historiografía y el "lugar del otro" como transversal para entender las barreras de la escritura de la historia respecto a la oralidad o la palabra, comprendiendo el binomio "salvajes-civilizados" (De Certeau, 2006, p. 211). Siendo la alteridad desde una identidad, también se desarrollan comparaciones entre Todorov y de Certeau, quienes trabajan la alteridad entre el control del texto y la textualidad, entre la historia ejemplar y la puesta en duda de la historia escrita, respectivamente (Adorno, 1991).

Creemos transversal a estas lecturas, las críticas poscoloniales desde espacios otrora colonias. La búsqueda de elementos comunes que otorguen a las nacientes repúblicas latinoamericanas un sentido de pertenencia al territorio fue uno de los grandes desafíos que se dispusieron a realizar aquellos países que buscaban dejar atrás sus pasados coloniales. Sin embargo, en aquel ejercicio por construir una nueva historia, de paso no sólo se borró todo aquello perteneciente al reino español, sino también el pasado indígena. Si bien, podemos encontrar la figura mapuche como guerrero heroico, férreo opositor a los españoles y nunca vencido, en la construcción del ideario de Estado nación su figura transmuta para representar el retraso, lo primitivo, la barbarie que debía ser superada por la civilización. De tal modo, aquel otro que por siglos fue mirado desde aquella óptica barbárica, continúa siendo una figura que no se acopla a los afanes republicanos.

Aquella visión civilización-barbarie no es un fenómeno que surgió a principios del siglo XIX, sino que encuentra sus raíces en la modernidad producto de los procesos de expansión europea y posterior colonización. Dussel (2000) alude al eurocentrismo, donde "la civilización moderna se autocomprende como más desarrollada, superior” (p. 29). Bajo esta noción europea, la historia de la conquista, la colonia y mucho de aquello que conocemos referente a este período queda narrado y contado durante generaciones con un sesgo que no incluye a la otredad y su visión de lo acontecido.

Desde los estudios subalternos, la realidad presente en la historia nacional posee grandes similitudes con la realidad presente en la apuesta teórica de autoras como Gayatri Spivak, filósofa dedicada a entender la posición del otro en la India tras la descolonización europea. Sus estudios de subalternidad con un enfoque poscolonial no sólo comprenden la relación desde una contraposición a los grupos dominantes o hegemónicos en las relaciones sociales y políticas (Gramsci, 1999), sino complejizando la caracterización de subordinados en tanto raza y género, como una crítica a las definiciones homogeneizantes de mujer o la etnia. Los estudios subalternos se vuelven una declaración de intenciones en la búsqueda de hacer frente 
a la escritura de la historia desde las élites. Una apuesta de escritura antielitista desde el tercer mundo, cercana a la historia desde abajo de ingleses como Hobsbawm, Hill y E. P. Thompson, considerando a los grupos subalternos como sujetos históricos (Sandoval, 2010).

En correlato con lo planteado anteriormente, Spivak (2003) señala que la otredad en contextos poscoloniales, como es el caso de la India y América Latina, se encuentra subsumida a una narración protagonizada primero por la dominación europea y luego por las élites coloniales. No obstante, es importante señalar también aquello que ha sido planteado por Silvia Rivera Cusicanqui como crítica a las líneas de pensamiento que se han dedicado a trabajar temáticas vinculadas a lo indígena. Señala que no se debe dejar de lado "las dinámicas internas de los subalternos", puesto que "pueden ser tentados a reproducir el ventriloquismo y la alambicada conceptualización que los aleja de sus raíces y de sus diálogos con las masas movilizadas" (Rivera Cusicanqui, 2010, p. 69). Estos planteamientos los veremos reflejados a su vez en las críticas realizadas por autores mapuche, más adelante.

Los estudios subalternos no solamente se han referido a la posición de la otredad en el marco del imperialismo, sino también al rol de lo femenino en la historia. Spivak (2003) señala que "la pista de la diferencia sexual está doblemente suprimida (...) Si en el contexto de la producción colonial el subalterno no tiene historia y no puede hablar, el subalterno como femenino está aún más profundamente en tinieblas" (p. 328). De este modo, la escritura de la historia narrada desde lo masculino, desde la postura vencedora, desde la mirada primermundista, somete a la otredad a una invisibilidad que impide retratar sus realidades y posturas en los marcos históricos que se buscan resaltar.

Nos interesa entender la subalternidad respecto a identidades que son comprendidas como un otro (u otra) en la narrativa histórica escolar, considerando que hay una crítica poscolonial que nos permite incorporar categorías como interseccionalidad en el debate, es decir, la importancia del análisis de clase, etnia y género en los estudios subalternos. De esta forma, el análisis del discurso de la historia a nivel curricular debe considerar las categorías propuestas, sobre todo cuando detrás de los proyectos de educación desde la institucionalidad se generan discursos determinados asociados a la historia oficial, como ya hemos señalado.

\section{Reformas educativas en Chile: control social y poder}

En las transformaciones curriculares que vive constantemente la educación, se reconoce un ejercicio de poder persistente en la historia de todos los países, específicamente mediante las reformas educativas. Se establecen condicionantes como estándares de conocimiento y habilidades, pauteados para lograr un buen funcionamiento de un sistema político económico mayor. Aquí se desprende el concepto de control social, que en la educación se concreta con las reformas para mejorar la calidad de esta misma, a través, por ejemplo, de instrumentos estandarizados de evaluación (Vázquez, 2015). Según Michael Apple (1997) el currículum es un medio donde el poder se valida mediante el ejercicio pedagógico, expresando competencias estructuradas y establecidas, que son medidas o evaluadas en el proceso educativo que conlleva un "adiestramiento" aplicado por los establecimientos educacionales. 
Dado quelas instituciones educativas funcionan en base alas directrices gubernamentales reflejadas en reformas o actualizaciones curriculares, el modelo político y económico es capaz de adentrarse a las ideologías y cuerpos del estudiantado, moldeando conductas y actividades, en base a competencias ya establecidas. En tanto las reformas educativas corresponden a un proceso político de renovación ideológica, Apple (1997) contempla la idea de que cualquier cambio político involucra una adaptación al sistema neoliberal, es decir, que estos cambios se rigen por patrones que van más allá de un bienestar educativo como tal, aportando al buen funcionamiento del mercado, que dicho sea de paso perpetúa desigualdades y segregaciones sociales reproduciendo "una fuerza de trabajo organizada jerárquicamente" ( p. 114).

Considerando a la escuela como una biopolítica en sí(Grinberg, 2010), dondelas narrativas y discursos gubernamentales se imprimen en los saberes y cuerpos del estudiantado, se puede vislumbrar un patrón normalizador que cumple el objetivo de modelar a la población para la aceptación social o laboral, descuidando el sentido de pertenencia o incluso despojando de culturas ancestrales o tradicionales. Esto se refleja en los espacios escolares, donde se siguen los patrones gubernamentales establecidos (reformas o actualizaciones en el currículum) que imposibilitan un entendimiento con su pasado histórico o familiar, un encuentro entre sus saberes y su propia vida, ya que las reformas efectivas en la enseñanza no son capaces de ver el sentido de la educación como algo netamente técnico, útil para formar individuos que respondan y accedan sin cuestionar, por ejemplo, la misma desigualdad que le rodea en el presente, en correlato con el pasado.

El poder ejercido por las reformas educacionales, con estrategias pedagógicas nuevas expresadas en sugerencias didácticas en los textos entregados a docentes y estudiantes, se concreta cuando los agentes y dispositivos de la educación (familia, jóvenes, docentes, programas pedagógicos, currículum, proyectos en las escuelas, administración) son capaces de adaptar estos términos y directrices en su quehacer educativo. María Marano (2004) denomina esta acción como política hegemónica, donde se generan posibilidades de apropiación del poder por intermedio de cambios estructurales en la educación.

Comprendemos que la narrativa presente en el currículum es un ejemplo de esta acción política hegemónica, ya que es precisamente en este instrumento que se concretan los discursos de las reformas educativas. Para ello, desarrollamos un análisis de las bases curriculares en relación a las reformas educativas en Chile entre 2010 y 2019, ya que establecen las directrices institucionales de los contenidos presentes en el currículum escolar. Esto último, considerando que hay una herencia de reformas que se arrastran desde los años noventa, y que nos permiten comprender la trayectoria de estos procesos de cambio y continuidad.

\section{SOBRE LAS REFORMAS EDUCATIVAS EN CHILE RECIENTE (1990-2019)}

Las reformas educativas que se han presentado después de la dictadura civil militar transparentan un sistema con bases en intereses económicos, como también un quiebre democrático con el Estado Docente que potencia una desigualdad educativa de larga duración (Illanes, 2008). Para los efectos de estos artículos, queremos centrarnos en las transformaciones 
más recientes, considerando como punto de partida la transición "a la democracia” y el legado dictatorial neoliberal. Desde que en 1990 se aprobara una transformación e "innovación" en el currículum nacional apoyado por el Banco Mundial, Chile fue el primer país en fomentar la equidad y calidad en la educación (Donoso, 2005), términos que se fueron apropiando en la gestión, administración y aplicación educativa, con el objetivo de aumentar el nivel educacional de la población, donde la enseñanza se basaría en competencias dirigidas al desarrollo en el mercado laboral.

De esta manera, la educación chilena se benefició en nueva infraestructura y materiales pedagógicos. En el ámbito docente, se transformaron los estatutos y se implantó un currículum flexible, que le dio cierta libertad al profesorado en estrategias y metodologías de enseñanza. Estas transformaciones fueron visibles recién seis años después de su promulgación (Donoso, 2005), con una educación constructivista que tenía como símbolo indiscutible la Jornada Escolar Completa (JEC) y el cambio en el espacio educativo/laboral de todas las comunidades educativas.

En términos técnicos, un gran ejemplo de transformación curricular vivida en la década de los noventa es la división en objetivos formativos del sistema educacional chileno. Éste buscó, por un lado, educar con el objetivo de fomentar conocimientos científicos humanistas con miras a la educación superior y, por otro lado, fortalecer la educación técnico profesional (TP), dirigida a preparar al estudiantado al mercado laboral. De lo último expuesto, Cariola y otros autores (2003) plantean que la educación TP, comparada con la científica humanista, se fue conformando como un sistema rígido, ya que el futuro formativo sólo limitaba al estudiante a continuar una educación técnica superior, considerando el currículum y los conocimientos adquiridos. Los autores afirman que este legado, adquirido en dictadura, no fue transformado del todo; es más, la educación en general no logró una adecuada renovación.

Vázquez (2015) plantea que la educación, desde los noventa, ha vivido para responder a estándares de calidad, donde las evaluaciones estandarizadas son los pilares del sistema educacional. Se mercantiliza educación, dejando de lado, por ejemplo, el aprendizaje de habilidades para poner énfasis en conocimientos necesarios que ayuden al mercado y su buen funcionamiento. De aquello es preciso destacar que la idea de segregación va permaneciendo y adueñándose cada vez más en comunidades, proyectos y programas en las escuelas.

De esta forma, el análisis de la narrativa curricular en historia permite comprender esta avanzada del mercado, considerando que el discurso se enmarca en reformas educativas que, al menos en los últimos nueve años, han fortalecido relatos ligados a los sujetos como buenos consumidores y/o mano de obra calificada para la institucionalidad neoliberal. Nos interesa reconocer elementos que cambiaron o prosiguieron en las reformas educativas posteriores, sobre todo entre 2009 y 2019.

Impacto de las reformas educativas en el currículum de historia, 2009-2019: Análisis desde la LGE y sus modificaciones

La actualización curricular ejecutada de 2009 responde a la necesidad de adaptar la realidad nacional a los conocimientos, habilidades y aptitudes de los y las estudiantes, al alero de los pilares educativos establecidos en los años noventa, donde la calidad y la equidad de la educación son los 
factores que posibilitan nuevas metodologías para formar ciudadanos y trabajadores a beneficio de la nación. De acuerdo con lo anterior, las actualizaciones curriculares se trabajaron en base a una perspectiva política, ética y antropológica (Decreto 280, 2009). Así se plantearon nuevos conceptos que dirigieron el currículum de Historia, Geografía y Ciencias Sociales, como son los Objetivos Fundamentales (OF), Objetivos Fundamentales Transversales (OFT) y los Contenidos Mínimos Obligatorios (CMO), que no se cambiaban desde 1996.

En la asignatura de Historia, Geografía y Ciencias Sociales, los OF y los OFT aportaron a una construcción diversa del estudiantado, pretendiendo promover un pensamiento reflexivo y respetuoso con las diversidades culturales existentes en la realidad nacional, como también fomentar una participación activa en la sociedad, enfatizando en el aprendizaje del pasado para la comprensión de la sociedad. De esta manera, la actualización curricular realizada en el 2009 se dirigió a renovar los contenidos de $1^{\circ}$ y $2^{\circ}$ medio; destacando que en nivel de $1^{\circ}$ medio el objetivo será otorgarle al estudiantado una visión del siglo XX a nivel mundial, problematizando la sociedad actual; por otro lado, en $2^{\circ}$ medio, se presenta como contenido la historia de Chile del siglo XIX, tomando como gran objetivo el diálogo entre la conformación del territorio y los relatos historiográficos (MINEDUC, 2009).

En la Tabla 1 podemos apreciar el listado de reformas y ajustes curriculares promulgados entre los años 2009 y 2019, considerando que la prosecución de éstos tiene estrecha relación con los procesos de movilización estudiantil y docente durante la última década. Para los efectos de este artículo y el posterior análisis de textos escolares, nos centraremos en las reformas de 2009, 2013 y 2015, ya que allí residen los principales cambios en la narrativa y priorización de contenidos y objetivos:

Tabla 1. Ajustes curriculares 2009-2019.

\begin{tabular}{|c|c|c|}
\hline Fecha de promulgación & Norma & Descripción \\
\hline 26-junio-2009 & Decreto 254 & $\begin{array}{l}\text { Modifica Decreto Supremo } \mathrm{n}^{0} 220 \text {, de } 1998 \text {, del Ministerio de Educación } \\
\text { que establece los objetivos fundamentales y contenidos mínimos } \\
\text { obligatorios de la educación media y fija normas generales para su } \\
\text { aplicación }\end{array}$ \\
\hline 16-diciembre-2009 & DFL 2 & $\begin{array}{l}\text { Fija texto refundido, coordinado y sistematizado de la Ley } \mathrm{N}^{0} 20.370 \text { con } \\
\text { las normas no derogadas del Decreto con Fuerza de Ley } \mathrm{N}^{\circ} 1 \text {, de } 2005\end{array}$ \\
\hline 25-marzo-2011 & 645 exento & Modifica Decreto No2.272 exento, de 2007 \\
\hline 24-diciembre-2013 & 614 & $\begin{array}{l}\text { Establece bases curriculares de } 7^{\circ} \text { año básico a } 2^{\circ} \text { año medio en } \\
\text { asignaturas que indica }\end{array}$ \\
\hline $\begin{array}{l}\text { 18-marzo-2014 (fecha } \\
\text { publicación) }\end{array}$ & Aviso $\mathrm{s} / \mathrm{n}$ & $\begin{array}{l}\text { Complementa publicación del Decreto Supremo } \mathrm{N}^{\circ} 614 \text {, de } 2013 \text {, del } \\
\text { Ministerio de Educación, que establece las bases curriculares de } 7^{\circ} \text { año } \\
\text { básico a } 2^{\circ} \text { año medio, en asignaturas que indica, publicado en la edición } \\
\text { del Diario Oficial } N^{\circ} 40.798 \text {, del día } 4 \text { de marzo de } 2014\end{array}$ \\
\hline 01-septiembre-2015 & 369 & $\begin{array}{l}\text { Establece bases curriculares desde } 7^{\circ} \text { año básico a } 2^{\circ} \text { año medio, en } \\
\text { asignaturas que indica }\end{array}$ \\
\hline 17-junio-2019 & 193 & $\begin{array}{l}\text { Aprueba bases curriculares para los cursos de } 3^{\circ} \text { y } 4^{\circ} \text { año de educación } \\
\text { media, en asignaturas que indica }\end{array}$ \\
\hline
\end{tabular}

Elaborado por las autoras. Fuente: Decretos del MINEDUC, disponibles en www.leychile.cl 
En correlato con estos elementos, situamos en este período polémicas como las disminuciones de horas de historia propuestas por el Ministro de Educación Joaquín Lavín en 2010 para aumentar las horas de lenguaje y matemáticas (El Mercurio, 2010), o el cambio en la denominación “dictadura” por "régimen militar”, que involucró al CNED y la encargada de la Unidad de Currículum y Evaluación del MINEDUC, Loreto Fontaine (Cooperativa, 2012). Respecto a la idea planteada por Lavín, el historiador Sergio Grez planteó para ese entonces que la disminución de horas de historia para mejorar lectura, escritura y habilidades matemáticas fue un mero pretexto político y antidemocrático: "La historia no es una simple memorización de fechas y de hechos (...) los alumnos aprenden o mejoran (...) su capacidad de exponer ideas lógicas, coherentes, su capacidad de exposición, de raciocinio, de inferir, su capacidad de construir discursos" (La Tercera, 2010).

En este punto es necesario comentar que para el período de tiempo que decidimos abarcar, se fortalecieron figuras como el CNED, que fue fijado por el Decreto con Fuerza de Ley N²-2009 de Educación, como respuesta a las demandas levantadas por el movimiento estudiantil en $2006^{2}$. Como señala Ruz-Fuenzalida (2019), la creación de estos organismos, sumado a la reformulación de objetivos y contenidos mínimos hacen de esta reforma la más ambiciosa e importante, considerando que buscó fortalecer la coherencia de la progresión curricular, cimentando el camino para los posteriores ajustes. Es necesario ahondar también en la propia conformación del CNED y quienes lo integran, siendo un espacio que, según sus actas y considerandos, "legalmente puede aprobar los planes y programas de estudio para la educación básica y media, propuestos por el Ministerio de Educación para ser aplicados en establecimientos educacionales que carezcan de planes y programas propios" (CNED, 2017, p. 1), aprobar o rechazar bases curriculares emanadas del MINEDUC, subvenciones de establecimientos educativos, además de su implicancia en la acreditación de universidades, centros de formación técnica e institutos profesionales.

Así como la LGE reemplazó a la LOCE, el CNED sustituyó al Consejo Superior de Educación (CSE) creado durante la dictadura cívico-militar ${ }^{3}$ (El Quinto Poder, 2019). Las críticas realizadas al CNED se vinculan a su conformación ${ }^{4}$, a la toma de decisiones en

2 A pesar de que nos centraremos brevemente en los alcances que tiene el CNED más adelante, nos interesa recalcar que la burocracia educativa será protagónica en la toma de decisiones como la eliminación de obligatoriedad de Historia en 3ro y 4to medio durante 2019, tensionando las relaciones con organismos como el Colegio de Profesores. "Colegio de profesores realizó una presentación ante la Contraloría por la reforma curricular”, ADN Radio Chile, 15 de julio de 2019. Recuperado de https://www.adnradio.cl/nacional/2019/07/15/colegio-deprofesores-realizo-una-presentacion-ante-la-contraloria-por-la-reforma-curricular-3927486.html (consultado el 23 de mayo de 2020).

3 El siguiente artículo de prensa destaca que el CSE estuvo conformado por un ex agente de la Central Nacional de Inteligencia (CNI), Ewing Pinochet. Recuperado de https://www.elquintopoder.cl/educacion/el-consejo-nacionalde-educacion-y-la-impronta-antidemocratica-del-curriculum-escolar/

4 El CNED está compuesto por diez miembros, quienes permanecen seis años en sus cargos, renovándose sólo la mitad cada tres años. Además, de los diez integrantes, uno es designado directamente por el mandatario/la mandataria de turno, sumados a cuatro también propuestos por la misma autoridad en base a su "prestigio". Se suman dos cargos para profesionales de la educación del ámbito privado y público, nombrados también por el Presidente o la Presidenta, mediante una terna realizada a través del Consejo de Alta Dirección Pública. Se agregan dos cargos propuestos por el Consejo de Rectores de las Universidades chilenas (CRUCh) y por las universidades privadas autónomas acreditadas y un cargo correspondiente a institutos profesionales y centros de formación técnica. Información en www.cned.cl 
lo que concierne al currículum nacional (o la misma narrativa de la historia escolar, por ejemplo), y la manera en que opera la elección de sus miembros. Así lo expresa Rosario Olivares de la Red de Profesores de Filosofía de Chile en el marco de la discusión de la supresión de la asignatura: "El CNED no es un órgano representativo ni democrático para decidir qué se enseña y qué no en Chile" (El Desconcierto, 2018). Con respecto a su conformación, Mario Aguilar, presidente del Colegio de Profesores, señaló que "el CNED ha terminado siendo un organismo de cuoteo político entre el duopolio de la Nueva Mayoría y la derecha". Tanto la página del CNED ${ }^{5}$ como los dichos por docentes en declaraciones de prensa apuntan a la falta de sentido público de sus integrantes ( $E l$ Desconcierto, 2018).

Las críticas también apuntaron a la Unidad de Currículum y Evaluación, coordinada en 2012 por Loreto Fontaine ${ }^{6}$. En este espacio se instaló la polémica por el cambio de nombre de "dictadura" por "régimen militar", lo que fue ampliamente criticado por profesores e historiadores. La historiadora Sofía Correa comentó que sabía que hubo un inicial rechazo por parte del CNED, y que la segunda presentación fue aprobada y estaba en trámite: "Lo hemos visto y analizado, encontrando allí un sesgo ideológico muy fuerte, un empobrecimiento de las habilidades y aprendizajes esperados" (El Mostrador, 2012). Hay trabajos que analizan la resolución del Ministerio y la relación con el poder que tiene la historia, más allá de lo discursivo, y los embates del MINEDUC como imposiciones de una "nueva versión del pasado" sin rigurosidad en el trato de los hechos, las fuentes, sino "una interpretación, de una lectura impuesta por las mismas fuerzas sociales y políticas que modificaron a sangre y fuego el desarrollo histórico de nuestro país el 11 de septiembre de 1973" (Cerda, 2012, p. 113).

La actualización curricular entre el 2013 y 2015 también se basó en continuidad con los planteamientos del 2009 en tanto principio de libertad de enseñanza, sólo que esta vez con el objetivo de innovar conocimientos disciplinares entre 1990 y 1998 (MINEDUC, 2015). Se especificó que las modificaciones responden a los requerimientos específicos de la LGE, adaptando los contenidos y objetivos según cada nivel educativo. Esto buscó fomentar la responsabilidad ciudadana y el respeto por su entorno, promoviendo "un aporte significativo para enfrentar los desafíos de desenvolverse en un mundo cada vez más dinámico, plural y cambiante" (MINEDUC, 2015, p. 176). Es decir, nuevamente se cambiaron los contenidos de $1^{\circ}$ y $2^{\circ}$ medio: en el primer nivel los CMO fueron dirigidos al estudio del siglo XIX y el segundo nivel el siglo XX, ambos toman una perspectiva mundial, latinoamericana y nacional, en los siglos correspondientes.

5 En efecto, la mayor parte de los miembros que conforman el CNED, se encuentran ligados a universidades privadas como la Universidad del Desarrollo y la Universidad de Los Andes, así como a establecimientos educacionales privados como el Saint George's College de la comuna de Vitacura y el Colegio San Francisco Javier de la comuna de Huechuraba. Información disponible en línea en https://www.cned.cl/consejeros (consultado el 2 de junio de 2020).

6 Cabe señalar que, según la página oficial del Consejo Nacional de Educación, Loreto Fontaine es actualmente miembro del CNED, por el período 2015-2021 "propuesta por la Presidencia de la República y ratificada por el Senado, a partir de una terna conformada por el Consejo de Alta Dirección Pública". Información disponible en línea en https://www.cned.cl/consejeros (consultado el 2 de junio de 2020). 
P. Arcos et al.

En relación a lo anterior, en marzo de 2013 se publicó Decreto 614 que estableció las bases curriculares de $7^{\circ}$ básico a $2^{\circ}$ medio para diversas asignaturas, entre ellas historia, donde se instó a que las y los estudiantes reconozcan las instituciones en la democracia chilena: "que comprendan los hitos, procesos e ideas fundamentales de la historia de Chile y de la humanidad que han tenido relevancia para la conformación actual de la sociedad chilena" (MINEDUC, 2014, p. 10).

Según la LGE los objetivos generales apuntaron por un lado a la puesta en valor de la historia y la geografía de Chile, la importancia de la institucionalidad democrática y cívica; y, por otro lado, conocer los "principales hitos y procesos de la historia de la humanidad y en especial aquellos aspectos de carácter político, cultural y religioso de relevancia para la sociedad chilena y tener conciencia de ser parte de un mundo globalizado" (Art. 30, n²). Asimismo, aparece un apartado posterior ligado al conocimiento indígena en tanto historia y cultura (Ley 21092, Art. único D.O. 23.05.2018). Este llamado se concreta en la difusión de bases curriculares, planes, programas y guías para docentes, donde se incorporaron elementos como contenidos, propuestas de actividades y orientaciones pedagógicas asociadas a la narrativa histórica para $1^{\circ}$ y $2^{\circ}$ de enseñanza media. En medio de los ajustes curriculares entre 2014 y 2015 se distribuyeron documentos como las Orientaciones y guiones didácticos para docentes. Estos ejemplares, dirigidos a docentes de $1^{\circ}$ y $2^{\circ}$ medio, poseen premisas orientadas a la educación como derecho social en donde confluye un estudiantado diverso. Este reconocimiento de la diversidad, de la vulnerabilidad socioeducativa, al mismo tiempo fortaleció la autonomía de los establecimientos desde el principio de libertad de enseñanza (MINEDUC, 2015).

Más específicamente, para lo que respecta a la asignatura de Historia, Geografía y Ciencias Sociales, se referenció lo señalado en la reforma de 2009 en tanto comprensión de la sociedad, en proyección y promoción de los cambios acelerados del presente, considerando a su vez el rol del profesorado de Historia, el desarrollo del pensamiento histórico y la problematización de la realidad social de docentes y estudiantes (MINEDUC, 2015).

Tanto en el texto dirigido a $1^{\circ}$ como a $2^{\circ}$ medio nos encontramos con este elemento común, además de una declaración de principios que caracterizó al docente como "constructor del currículum" y que permite "contextualizar" en el espacio y tiempo, con una redacción que apunta a hechos y procesos históricos, y levemente a los sujetos cuando se habla de explicaciones multicausales y las diferentes dimensiones de lo social en el proceso de enseñanza y aprendizaje de Historia: "Reconocen los personajes, grupos, sociedades o entidades que generan y protagonizan las acciones que serán objeto de explicación" (MINEDUC, 2015, p. 23). En lo que respecta a la explicación multicausal que tendrían los estudiantes, se menciona que una dificultad es poder tratar "estados emocionales de ciertos personajes o figuras históricas” (MINEDUC, 2015, p. 24). Llama la atención este punto, ya que se relaciona con la "historia-materia” (Vilar, 1999), la de los personajes y los datos; narrativa de la historia enmarcada en los procesos y hechos como marco para el discurso histórico que se pretende presentar. Aun así, según los ajustes curriculares, este documento sólo fue un refuerzo de las reformas curriculares de 2009. En septiembre de 2015 se promulgó el Decreto 369 que estableció las nuevas bases curriculares, de $7^{\circ}$ básico a $2^{\circ}$ medio. 


\section{NARRATIVA HISTÓRICA EN LOS TEXTOS DEL ESTUDIANTE DE $1^{\circ} \mathrm{Y} 2^{\circ}$ MEDIO: MUJERES Y PUEBLOS ORIGINARIOS EN EL RELATO ESCOLAR}

Marc Ferró (1993) en Cómo se cuenta la historia a los niños del mundo entero recorre los relatos hegemónicos y la invisibilización que éstos generan: una historia blanca, de los vencedores, conquistadores, colonizadores y forjadores de la nación tal y como se busca difundir en los textos de estudio. En correlato con las bases curriculares analizadas, revisamos la narrativa presente en los textos escolares en el marco de las reformas de 2009 y 2013/2015, considerando las ediciones más actualizadas de los textos escolares de $1^{\circ}$ y $2^{\circ}$ medio.

Sobre los textos escolares, a pesar de que se reconoce que hay otra disposición al aprendizaje en los libros de historia, donde "ya no entrega el contenido digerido por su autor para ser aprendido de memoria, sino que propone situaciones a resolver con los diversos recursos que entrega y la guía de sus profesores" (El Mostrador, 2018), hay otros aspectos del relato que son objeto de análisis. La estructura de los textos, en general, responde a explicitar los CMO, actividades y referencias adicionales a las presentadas a lo largo de las unidades temáticas. Al respecto, analizaremos la subalternidad presente en la narrativa escolar, considerando a los pueblos originarios y las mujeres y su presencia/ausencia como sujetos en el relato dirigido a las y los estudiantes de $1^{\circ}$ y $2^{\circ}$ medio, en las unidades de aprendizaje donde se aborde la conformación del Estado nación chileno.

\section{Las mujeres en la narrativa histórica de la conformación del Estado Nación en Chile}

Considerando que el sistema educacional posdictadura se burocratizó con organismos como la Unidad de Currículum y Evaluación y el CNED este análisis se enfocará en los dos primeros años del ciclo de enseñanza media, teniendo presentes los cambios desde la narrativa histórica que los textos brindan a los y las estudiantes durante la última década. Estos textos, correspondientes a las editoriales Aguilar y Santillana para las respectivas reformas y ajustes curriculares, serán analizados a partir de la priorización de discursos, los cambios y continuidades, la presencia o ausencia de los sujetos históricos planteados desde un principio como la subalternidad para la historia oficial. En tabla 2 se expone, se comparan los cambios en temáticas de $1^{\circ}$ medio en el marco de las bases curriculares de los años 2009 y 2013/2015 (ver página siguiente).

Como se aprecia en el cuadro, se mantiene la "cantidad" de contenidos, habiendo leves transformaciones narrativas en las unidades. Considerando los CMO del 2009 y 2013/2015, en los textos escolares se define un relato desde la historia mundial que posteriormente es contrastada con la nacional, con un análisis de imágenes expuestas, actividades y temáticas propuestas a los/las estudiantes, identificando transformaciones sustanciales de la dinámica y sentido pedagógico del contenido. Respecto al contenido enfocado en la conformación del Estado nación en Chile, el currículum de 2009 para $1^{\circ}$ medio prioriza una narrativa de historia global, situada en hechos y procesos del siglo XX como las guerras mundiales y la guerra fría. Se observa que el texto de la editorial Aguilar (2009), el contenido titulado "Unidad 3: El mundo en Guerra Fría", se transforma con la editorial Santillana (2017), pasando a ser 
P. Arcos et al.

Tabla 2. Contenidos Historia, Geografía y Ciencias Sociales, $1^{\circ}$ medio (2009 y 2013/2015).

\begin{tabular}{|c|c|}
\hline $1^{\circ}$ medio 2009 & $1^{\circ}$ medio $2013 / 2015$ \\
\hline 1. La primera guerra mundial y el mundo & $\begin{array}{l}\text { 1. Estado-nación y sociedad burguesa en Europa } \\
\text { y América en el siglo XIX }\end{array}$ \\
\hline $\begin{array}{l}2 . \quad \text { La segunda guerra mundial y el nuevo } \\
\text { orden político internacional }\end{array}$ & $\begin{array}{l}\text { 2. La idea del progreso indefinido y sus } \\
\text { contradicciones: de la industrialización a la guerra } \\
\text { total en el cambio de siglo }\end{array}$ \\
\hline $\begin{array}{l}\text { 3. El mundo en la segunda mitad del siglo } \\
\mathrm{XX}\end{array}$ & $\begin{array}{l}\text { 3. El desafío de consolidar el orden republicano y } \\
\text { la idea de nación: Chile en el siglo XIX }\end{array}$ \\
\hline $\begin{array}{l}\text { 4. Los procesos de urbanización en el } \\
\text { siglo XX }\end{array}$ & $\begin{array}{l}\text { 4. Configuración del territorio chileno y sus } \\
\text { dinámicas geográficas en el siglo XIX }\end{array}$ \\
\hline 5. Geografía de la población mundial & $\begin{array}{l}\text { 5. El orden liberal y las transformaciones políticas } \\
\text { y sociales de fin de siglo en Chile }\end{array}$ \\
\hline $\begin{array}{l}\text { 6. El mundo globalizado con sus logros } \\
\text { y falencias }\end{array}$ & $\begin{array}{l}\text { 6. Formación económica: las personas y el } \\
\text { funcionamiento del mercado }\end{array}$ \\
\hline $\begin{array}{l}\text { 7. Habilidades de indagación, análisis e } \\
\text { interpretación }\end{array}$ & $\begin{array}{l}\text { 7. Formaciónciudadana:sociedadcontemporánea: } \\
\text { diversidad, convivencia y medioambiente }\end{array}$ \\
\hline
\end{tabular}

Elaborado por las autoras. Fuente: Objetivos Fundamentales y Contenidos Mínimos Obligatorios de la Educación Básica y Media, Actualización 2009 y Bases Curriculares $7^{\circ}$ básico a $2^{\circ}$ medio. Decreto Supremo de Educación N614/2013, Decreto Supremo de Educación N³69/2015. MINEDUC.

titulado "Unidad 3: Chile y el mundo durante la Guerra Fría". Esto demuestra que el objetivo estuvo en la comprensión de la historia nacional, después de estudiar y analizar el conflicto mundial.

Si enfocamos el análisis en el contenido ligado a la conformación del Estado nación, recién en las bases curriculares de 2013/2015 aparecen al menos cuatro unidades de aprendizaje referidas a la temática, que para 2009 era analizada durante $2^{\circ}$ medio. Desde la primera unidad y los idearios liberales que desencadenaron la independencia y posterior fundación de la república de Chile, hay claras intenciones de narración que integre a los sujetos históricos, aunque subsumidos en los hechos y procesos. Por ejemplo, cuando se señala la exclusión en la que permanecían las mujeres, homologadas a esclavos, indígenas y mestizos hacia el siglo XIX (MINEDUC, 2017). Asimismo, los roles de las mujeres, pero en la sociedad burguesa, como cápsulas o pie de página "los hombres generalmente se encargaban de los negocios, las relaciones públicas y la política; mientras que las mujeres, en la mayor parte de los casos, estaban recluidas en los espacios domésticos" (MINEDUC, 2017, p. 88). Sin embargo, páginas más adelante, como un apartado para finalizar la unidad, aparece una actividad con la siguiente reflexión, que apunta a ciertas presencias y ausencias: "Las burguesas, eran educadas para mantenerse en el ámbito de la vida privada, sin participar de la política y de la vida pública. ¿Crees que todas las mujeres siguieron este modelo?" (MINEDUC, 2017, p. 92).

Inclusive aparecen consignadas unas fotos y la declaración de Derechos de la Mujer y la Ciudadana de Olimpia de Gouges en 1791, y actividades donde se promueve la investigación 
de las y los estudiantes sobre mujeres destacadas nacionales e internacionales del siglo XIX y principios del siglo XX (MINEDUC, 2017). Lo central en la narrativa, sin embargo, sigue siendo la exposición de hechos y procesos que promovieron el nacimiento del Estado de Chile. De hecho, al menos para la primera mitad del siglo XIX chileno, no se señala ni siquiera la invisibilización en la que se encuentran las mujeres, más allá de las referencias a mujeres "destacadas" o de la burguesía.

Más adelante se referencia un pequeño extracto sobre la participación de la mujer en la guerra, con enlaces a pie de página que dirigen al portal "Memoria Chilena", para que estudiantes investiguen sobre la Sargento Candelaria. El extracto aboga por la mujer en la guerra del Pacífico, como una cooperadora en el campo de batalla, "alcanzando incluso grados militares, y que algunas lograron gran prestigio entre las filas y otras dieron muestras de heroísmo y sacrificio como las chilenas que perecieron en La Concepción” (MINEDUC, 2017, p. 217). A su vez aparecen en otros extractos mujeres de pueblos originarios, como el testimonio de una mujer selk'nam (MINEDUC, 2017), y la foto de una mujer mapuche junto a una niña, como se muestra en la Fig. 1. En esta última fuente, se encuentra la siguiente reflexión en torno a los roles de género, incluso referenciando a investigadores como José Bengoa o invitando al final de la fuente a investigar sobre las condiciones demográficas, sociales y económicas en que viven actualmente las mujeres mapuche y de otras comunidades indígenas (MINEDUC, 2017).
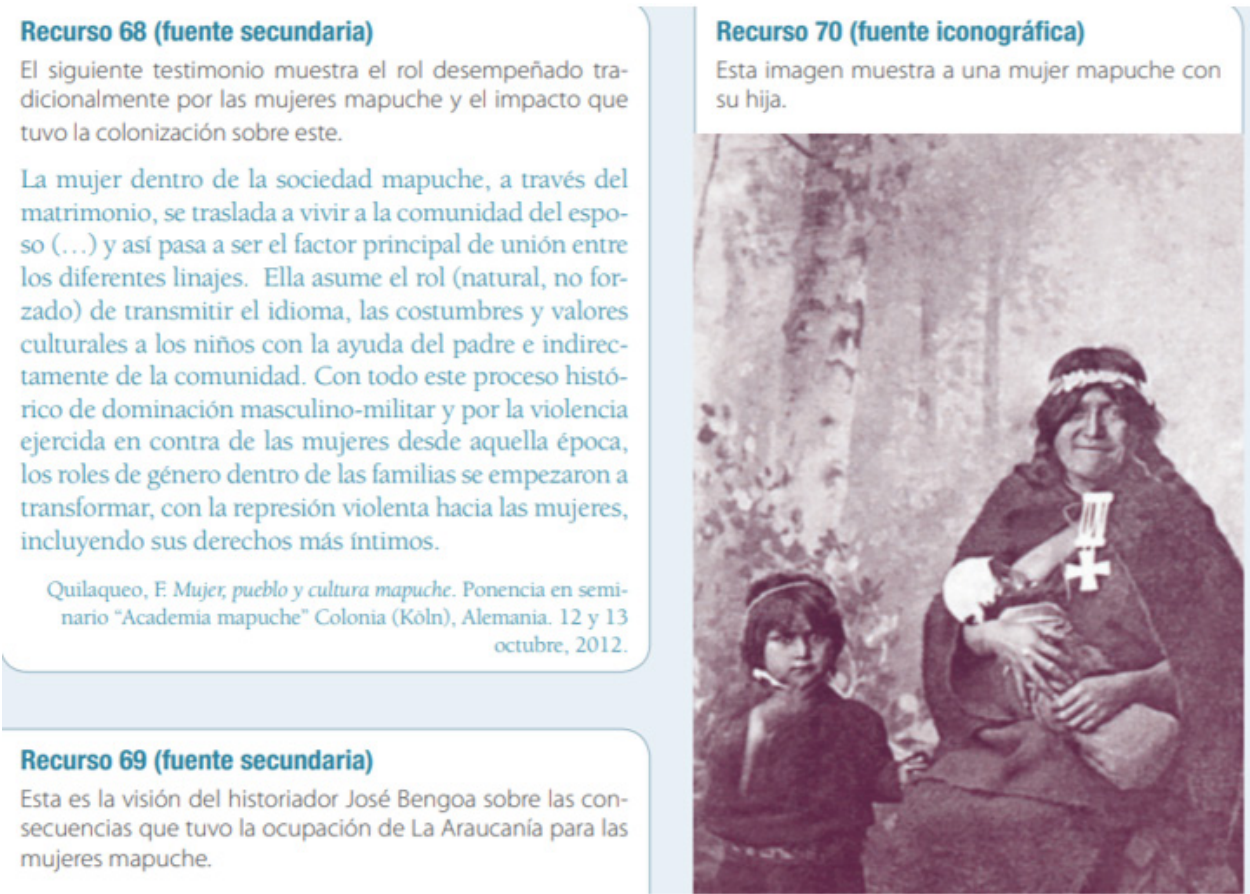

Fig. 1. Cápsulas de actividades Unidad 4 "La configuración del territorio chileno y sus proyecciones". Fuente: Texto del Estudiante $1^{\circ}$ Medio, Historia, geografía y ciencias sociales, MINEDUC, Editorial Santillana, edición 2017, p. 236.

1 El portal Memoria Chilena alberga recursos digitales e investigaciones basadas en documentos digitalizados de las colecciones de la Biblioteca Nacional de Chile. http://www.memoriachilena.gob.cl/602/w3-article-123834.html 
Considerando que el siguiente apartado referirá en específico al análisis sobre la presencia de los pueblos originarios en el relato de historia escolar, llama la atención esta presencia de fuentes que incluso apelan al impacto de la ocupación del territorio mapuche en las mujeres (MINEDUC, 2017). Hasta este punto del análisis, reconocemos que al menos hay un intento de narrativa histórica que presenta a sujetos históricos subalternos como las mujeres para la construcción y comprensión de la historia. A diferencia de lo que se identifica en el texto escolar de $1^{\circ}$ medio sobre el rol de "la nueva mujer" como un descubrimiento de ese período, la edición analizada y proveniente de la actualización de 2013 dejó de invisibilizar la trayectoria histórica de las demandas feministas o los movimientos de mujeres.

Por ejemplo, en el texto escolar de $1^{\circ}$ medio, edición 2014, enmarcado en la reforma de 2009 se expone que estas demandas "se centraron en la reivindicación de su rol en la sociedad y en su discurso de la igualdad. La emancipación en los anticonceptivos permitió controlar la natalidad y les abrió el camino para la liberación sexual” (p. 116). La narrativa histórica sólo se detiene en esos hitos, sin promover alguna posible identificación entre los y las jóvenes y las mujeres en la historia, considerando su rol en las crisis sociales, económicas, en la política, sino que son nombradas como grupo apartado del relato central, si es que llegan a aparecer, como el caso del texto escolar enmarcado en las reformas curriculares 2013/2015. Esto es algo en lo que también reparó Joan Scott (2008), considerando la corta trayectoria de la historiografía con enfoque de género y las posibles categorizaciones históricas: "más allá de la búsqueda ingenua de los antecedentes heroicos del movimiento de mujeres contemporáneo" (p. 36), sino que relevar la historia de las mujeres como experiencia ignorada, y problematizar en otras construcciones sociohistóricas, como el sistema sexo-género o la división sexual del trabajo en la historia. Como se muestra en la figura 2 del texto escolar en el marco de las reformas 2013/2015, donde se narra desde las mujeres notables, de la élite:

Si bien la historiografía ha puesto en debate el positivismo y los relatos de grandes procesos políticos, económicos y militares frente a la importancia de relatos que involucren sujetos, la narrativa escolar presente en las bases curriculares de 2009 insiste en relevar hitos que ignoran a los actores sociales, o que, si reconocen sujetos, son hombres (y algunas mujeres) notables que no se condicen con las realidades del estudiantado. Se relata una historia de los grandes exponentes de conflictos, pero no se identifica las consecuencias sociales del pueblo, de mujeres pobres, violentadas, de trabajos invisibles. El "nuevo rol de la mujer", como consigna el texto de la editorial Aguilar, está limitado al uso de anticonceptivos y el control natal, no hay análisis más profundos de las mujeres organizadas como movimiento social, su relación con el conflicto mundial no existe, ni mucho menos qué hay detrás de las demandas.

Mientras en el texto $1^{\circ}$ medio de 2013 (edición 2017) hay un análisis un poco más detallado del movimiento de mujeres, problematizando su trayectoria de acuerdo a la obtención del voto, nombrando sólo como complemento que además había luchas por derechos civiles, sociales y económicos. Incluso, como consignamos en las unidades referentes a la conformación republicana de Chile, la edición analizada presenta, al menos a pie de página, 

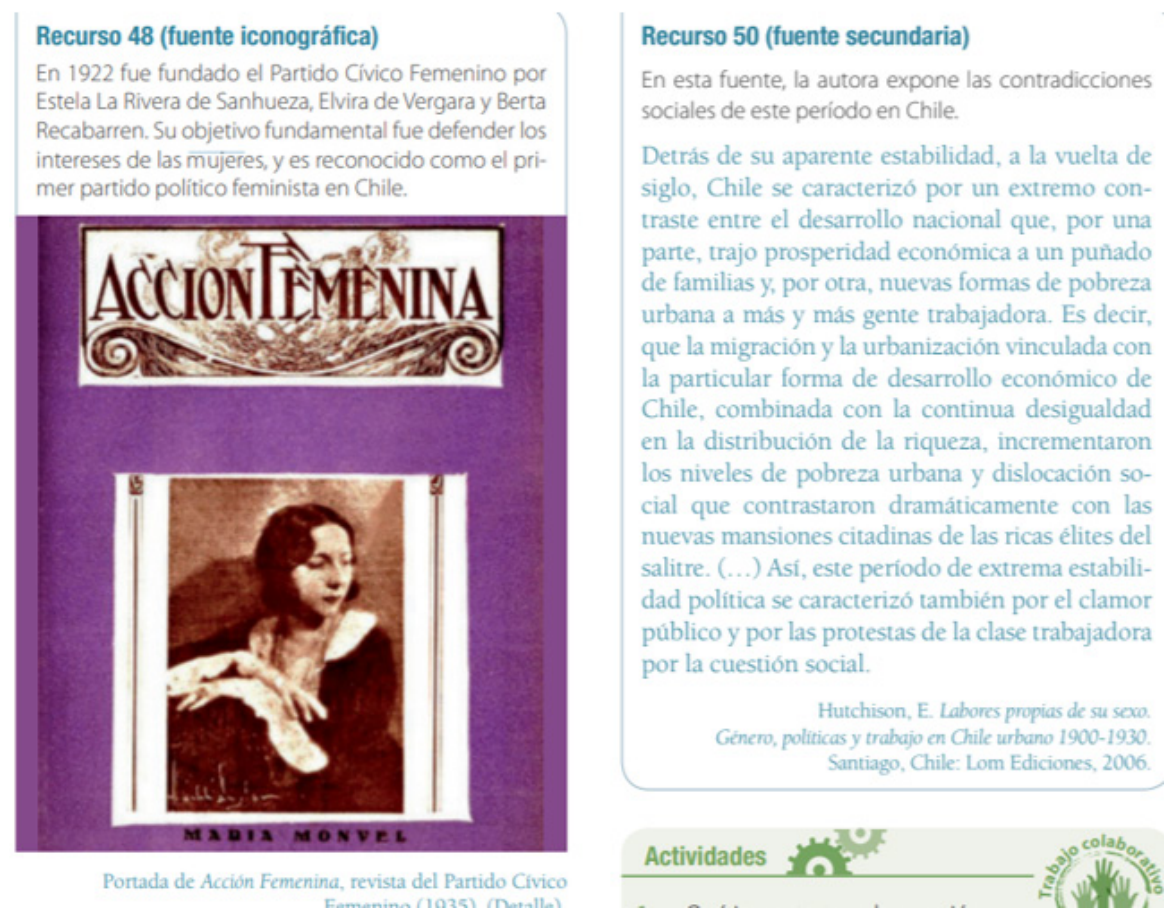

Fig. 2. Cápsulas de actividades Unidad 5 "El cambio de siglo en Chile y el mundo". Fuente: Texto del Estudiante $1^{\circ}$ Medio, Historia, geografía y ciencias sociales, MINEDUC, Editorial Santillana, edición 2017, p. 285.

con extractos o actividades anexas, la caracterización de otras mujeres, como las de pueblos originarios. La narrativa histórica expresada en este texto escolar apela a una comprensión del proceso desde un espacio donde los protagonistas siguen siendo hombres poderosos, o bien mujeres de la élite o notables.

\section{El otro indígena en la narrativa ministerial}

El tratamiento de la temática mapuche ha sido un campo historiográfico que no ha estado exento de polémicas. Los replanteamientos que se realizaron a la temática partieron desde la crítica a autores como Sergio Villalobos, por considerar que sus obras relevan la importancia de la conquista y sus aportes culturales. Así también, otros autores dedicados a la temática levantaron discursos que no criticaron el accionar del Estado frente a las demandas, y postulaban al mestizaje como un asunto clave a destacar. Durante muchos años los programas y textos escolares estuvieron construidos desde estos discursos, sin levantar visiones críticas, ni mucho menos replantear la forma en que se había construido la historia. En las décadas que sucedieron a la dictadura cívicomilitar, las bases curriculares y textos escolares plantearon debates que refieren al pueblo mapuche desde la óptica civilización/barbarie, como se señaló en el apartado teórico. En la Tabla 3 vemos la variación de contenidos en los textos escolares, considerando los tiempos de reforma: 
Tabla 3. Contenidos Historia, Geografía y Ciencias Sociales, $1^{\circ}$ medio (2009 y 2013/2015).

\begin{tabular}{|c|c|}
\hline $2^{\circ}$ medio 2009 & $2^{\circ}$ medio $2013 / 2015$ \\
\hline $\begin{array}{l}\text { 1. Persistencia de los pueblos y culturas } \\
\text { indígenas }\end{array}$ & $\begin{array}{l}\text { 1. Crisis, totalitarismo y guerra en la primera mitad del siglo } \\
\mathrm{XX}\end{array}$ \\
\hline El legado colonial & El fortalecimiento del Estado y la democratización social \\
\hline La conformación del Estado-nación & en el Chile de la primera mitad del siglo XX \\
\hline Las transformaciones liberales & De un mundo bipolar a un mundo globalizado: la Guerra \\
\hline $\begin{array}{l}5 . \quad \text { La inserción de la economía chilena en el } \\
\text { orden capitalista }\end{array}$ & $\begin{array}{l}\text { Fría } \\
\text { 4. Chile en el contexto de la Guerra Fría: transformaciones }\end{array}$ \\
\hline $\begin{array}{l}\text { 6. La conformación del territorio chileno y de } \\
\text { sus dinámicas geográficas }\end{array}$ & $\begin{array}{l}\text { estructurales, polarización política y social y quiebre de la } \\
\text { democracia }\end{array}$ \\
\hline $\begin{array}{l}\text { 7. La época del salitre y los grandes cambios } \\
\text { de fin de siglo }\end{array}$ & $\begin{array}{l}\text { 5. Dictadura militar, transición política y consenso en torno } \\
\text { a la democracia en el Chile actual }\end{array}$ \\
\hline $\begin{array}{l}\text { 8. Habilidades de indagación, análisis e } \\
\text { interpretación }\end{array}$ & $\begin{array}{l}\text { 6. Formación ciudadana: los derechos humanos y el Estado } \\
\text { de derecho como fundamentos de nuestra vida en sociedad }\end{array}$ \\
\hline
\end{tabular}

Elaborado por las autoras. Fuente: Objetivos Fundamentales y Contenidos Mínimos Obligatorios de la Educación Básica y Media, Actualización 2009 y Bases Curriculares $7^{\circ}$ básico a $2^{\circ}$ medio. Decreto Supremo de Educación N614 / 2013, Decreto Supremo de Educación N³69/2015. MINEDUC.

En el texto escolar de 2013 de la Editorial SM (correspondiente aún a la reforma de 2009), la temática que aborda la conformación del Estado nación excluye a los pueblos originarios como sujetos históricos. Siguiendo la lógica de las causas internas y externas, la revisión de este período se enfrasca en aquellos hechos que se remiten a los aconteceres políticos y sociales de Europa y Estados Unidos y las repercusiones en las colonias hispanoamericanas, con referencias a las élites locales y los conflictos criollos. Sólo un pequeño apartado menciona el impacto de la independencia en los sectores populares, destacando el trabajo realizado por la historiadora María Angélica Illanes. Finalmente, al momento de referirse a la construcción del Estado nación, se menciona la construcción de una identidad chilena, sin mencionar a los pueblos originarios explícitamente, sino para que el estudiante infiera algunos elementos, como muestra la Fig. 3 :

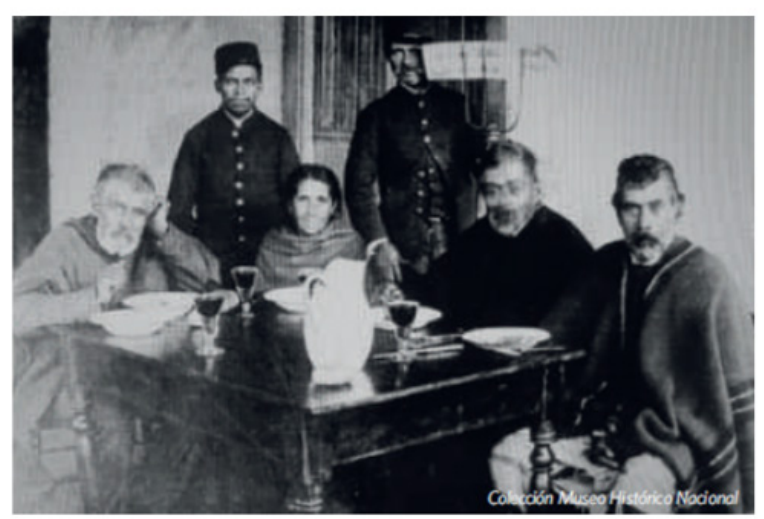

ACTIVIDAD N²7. Analizar cambios en un proceso histórico.

Observa la imagen y de acuerdo a lo que has estudiado, responde las preguntas.

3. Infiere cuál sería el papel que cumplía la mujer que aparece en la imagen. ¿Tenía los mismos derechos que los demás? ¿Por qué?

Fig. 3. Cápsulas de actividades Unidad 5 "El cambio de siglo en Chile y el mundo".

Fuente: Texto del Estudiante $2^{\circ}$ Medio, Historia, geografía y ciencias sociales, MINEDUC, Editorial SM, edición 2013 , p. 154. 
Para el período conservador en el que se inician las ocupaciones territoriales en el sur de Chile, la discusión bibliográfica se basa en autores como Sergio Villalobos, Mario Góngora, Cristián Gazmuri, Alfredo Jocelyn-Holt y Gabriel Salazar. No hay presencia de historiadoras ni mucho menos historiadores/as mapuche que trabajen la temática, pero sí intentos por contrastar los relatos historiográficos desde los historiadores mencionados. Acerca de la ocupación de la Araucanía en particular, no se expone en las páginas dedicadas al período conservador. Sólo se hace alusión a la colonización europea y la ocupación de Magallanes. No obstante, más adelante es posible encontrar una sección denominada "Dimensiones geográficas, políticas y económicas", en la que se desarrolla directamente la ocupación de la Araucanía, de Rapa Nui y de Magallanes. Si bien se aborda la situación de los pueblos selknam, aonikenk, yámanas y kawésqar desde la idea del exterminio y la limitación de sus territorios, a la hora de abordar la situación del pueblo Mapuche y Rapa Nui, dista de tratarse directamente como usurpación. Frente a la invasión y despojo del territorio mapuche en la Araucanía, se dice que,

Saavedra era partidario de favorecer la colonización extranjera y la entrega de tierras a los soldados de la Frontera, pero se oponía al despojo total de los indígenas. Otros dirigentes políticos y comandantes militares abogaron directamente por el exterminio de los mapuches. En la práctica, el plan de Saavedra fue el único que pudo implementarse, ya que la resistencia mapuche impidió la eliminación física de la etnia, aunque hubo numerosas masacres y otras acciones abyectas (MINEDUC, 2013, p. 195).

Esta cita demuestra un claro intento de instalar un discurso de consenso frente a aquello que continúa siendo el punto de partida de las demandas presentes en la lucha mapuche por la reivindicación territorial, a la vez que expone la clara intención de limpiar la imagen de uno de los personajes sindicados como principal responsable del despojo y exterminio, como es Cornelio Saavedra. Otro ejemplo es el siguiente episodio sobre Rapa Nui, donde hasta la actualidad en textos escolares y orientaciones curriculares, continúa abordándose como un acuerdo pacífico entre el pueblo Rapa Nui y el Estado chileno, expresado en el texto de la siguiente manera:

El Consejo de Ancianos, máxima autoridad de los habitantes de Isla de Pascua, además de la Iglesia católica y otras instancias, solicitaron en varias oportunidades al gobierno de Chile que asumiera la soberanía sobre la Isla debido a la desprotección en que se encontraban sus habitantes (MINEDUC, 2013, p. 193).

Sin embargo, no se hace referencia a los conflictos suscitados hasta la actualidad en el territorio, puesto que a partir del tratado de 1888 y desde la inscripción del territorio como chileno en 1933, sólo un 13,6\% de las tierras se encuentra en manos del pueblo Rapa Nui, dando paso hasta la actualidad al despojo y ocupación por parte de intereses privados ( $B B C$ News, 2011). 
Cabe señalar que, en la narrativa presente en el texto, los sujetos se encuentran en su relación de subalternos al poder, representado en este caso por el Estado chileno. Se evidencia que, tal como hemos señalado anteriormente, existe un sector de la sociedad dominante que silencia e inhibe a los demás sujetos históricos, de modo tal que aquella historicidad queda relegada de la construcción oficial narrada en los textos escolares. Sobre la continuidad de este contenido, tras la reforma realizada en 2013, la conformación del Estado nación se retoma de manera breve en los textos de historia posteriores a dicho año, por lo que no se realiza un análisis de esta temática (y la presencia/ausencia de los sujetos históricos correspondientes a este período) en cursos en los que, tal como indican las Orientaciones para la elaboración del Plan de Formación Ciudadana del año 2016, los y las estudiantes deben contar con competencias como pensamiento crítico y autonomía, además de habilidades y actitudes para construir una sociedad democrática, en miras al ejercicio de la ciudadanía (MINEDUC, 2016).

Haciendo un balance de la forma en que se ha trabajado dicho período, autores como Bengoa señalan el poco protagonismo que la historiografía ha tenido, tratando al pueblo mapuche desde la ambigüedad, entre ser ciudadanos o de otra nacionalidad, bárbaros, personas sin derechos civiles (Bengoa, 1999). Esta construcción de una narrativa y un discurso llevado a través de la educación se traduce en una concepción determinada acerca de las temáticas involucradas en la enseñanza de la historia en Chile colmada de "exclusión, ocultamiento, avasallamiento, imitación y renuncia de lo propio” (Pinto, 2003, p. 283) y que niegan a su vez la multiculturalidad que posee Chile.

Si se pone el foco en el desarrollo del pensamiento crítico desde la enseñanza de la historia, es de esperar que se integre en la narrativa y en el discurso a autores que construyen el conocimiento desde su propia tradición y en respuesta al contenido basado en historiadores obsoletos frente a los debates y dinámicas actuales. Un ejemplo es la historia mapuche y las alternativas que confrontan discursos instalados en el Chile posdictatorial sobre la propia cultura del pueblo, su lengua y la construcción de conocimiento: "Una Historia involucra analizar cómo se construye conocimiento desde lo mapuche, establecer los puntos de convergencia y de antagonismos con otras formas de conocimiento" (Marimán, Caniuqueo, Millalén \& Levil, p. 9). De tal modo, abordar lo mapuche desde sus propias voces y dar cabida así también a nuevas narrativas acerca de los pueblos originarios que integran la multiculturalidad del territorio que habitamos, es un desafío que debe plantearse en las futuras modificaciones curriculares.

\section{CONCLUSIONES}

Las movilizaciones estudiantiles y docentes por educación de calidad significaron la respuesta de la institucionalidad a través de reformas y ajustes curriculares en la última década. Para el caso de $1^{\circ}$ y $2^{\circ}$ medio, las bases curriculares y los textos escolares nos muestran que la construcción de la idea del otro, en el marco del contenido sobre la conformación del Estado nación, está atravesada por la hegemonía de la historia oficial que aboga por los hechos y procesos. En el marco de los ajustes curriculares, que entendemos como la 
respuesta de la institucionalidad a los movimientos estudiantil y docente de la última década, la relación entre las reformas y el currículum responde también a una pretensión de renovar las estrategias pedagógicas y potenciar una narrativa que reconozca los valores de la democracia y la globalización. Se reconoce que se han sumado temáticas en relación con la contingencia, sin embargo, la comprensión de las problemáticas actuales del país se suele suplir por sugerencias de actividades (para estudiantes) o estrategias (para docentes) que están atravesadas por la priorización de hitos, hechos y procesos que tributan a la construcción de un relato oficial.

Sobre la hipótesis, la narrativa histórica emanada desde las bases curriculares en los textos escolares de historia que analizan la conformación del Estado nación chileno continúa perpetuando una historia oficial, colonialista y patriarcal que invisibiliza discursivamente a los otros con el ajuste curricular de 2009, aunque se presentan algunos cambios en la narrativa de los textos escolares enmarcados en las reformas de 2013 y 2015. Hay una orientación discursiva en los textos escolares de la asignatura de historia, donde los temas ligados a mujeres y pueblos originarios aparecen como anexos o cápsulas de la historia nacional, y no son transversalizados en los CMO o en los Objetivos de Aprendizaje (OA). Los sujetos subalternos de la historia que no participaron de batallas o de logros importantes para el nacimiento de la república (como los pueblos originarios o las mujeres, según las bases curriculares de 2009 y 2013/2015) permanecen como extractos de investigación que quedan a criterio de la autonomía del estudiante, la libertad de enseñanza del docente o el proyecto educativo de cada establecimiento. Consideramos que esto provoca una desvinculación o un desinterés por la historia, no hay identificación del estudiantado como sujetos históricos o para la comprensión de su propia historia.

Creemos que un currículum en historia que promueva la subalternidad otorga la complejidad reflexiva necesaria en la narrativa de la escuela, pues acerca al estudiantado a vivencias y problemáticas similares, que incluso perduran en el tiempo, facilitando la comprensión, identificación y profundización de las temáticas a tratar. En tiempos en donde son frecuentes frases como "nadie lo vio venir" o "esto nunca había ocurrido", la narrativa histórica se vuelve transversal para comprender el pasado respondiendo las preguntas de nuestro presente y proyectando futuro, considerando la construcción de la experiencia desde abajo, desde los actores silenciados por el relato oficial, y que desde diversas corrientes e incluso movimientos sociales, han protagonizado la demanda por la visibilización en el currículum y en la práctica cotidiana.

\section{REFERENCIAS}

Adorno, R. (1991). Todorov y de Certeau: La alteridad y la contemplación del sujeto. Revista de Crítica Literaria Latinoamericana, 17(33), 51-58.

Anderson, B. (1993). Comunidades imaginadas. Reflexiones sobre la difusión y el origen del nacionalismo, México: FCE.

Apple, M. (1997). Teoría crítica y educación. Buenos Aires: Miño y Dávila editores.

Bautista, J. (2014). ¿Qué significa pensar desde América Latina? Madrid: Ediciones Akal. 
P. Arcos et al.

Bengoa, J. (1999). Historia de un conflicto. El Estado y los Mapuche en el S. XX. Santiago: Editorial Planeta.

Cariola, L., Bellei, C., \& Núñez, I. (2003). Veinte años de políticas de educación media en Chile. París: UNESCO Instituto Internacional de Planeamiento de la Educación.

Carretero, M., \& Kriger, M. (2004). ¿Forjar patriotas o educar cosmopolitas? El pasado y el presente de la historia escolar en un mundo global. En M. Carretero \& J. F. Voss (Comps.), Aprender y pensar la historia. España: Amarrortu Editores.

Cerda, C. (2012). La historia del poder y el poder de la Historia: a propósito del intento que hace una minoría social por borrar las huellas de sus horribles crímenes cometidos en el pasado. Cuaderno de trabajo social. Departamento de Trabajo Social UTEM, 5, 108-124.

Certeau, M. D. (2006). La escritura de la historia. Universidad Iberoamericana, México.

Donoso, S. (2005). Reforma y política educacional en Chile 1990-2004: el neoliberalismo en crisis. Estudios pedagógicos, 31(1), 113-135. Recuperado de https://doi.org/10.4067/ S0718-07052005000100007

Dussel, E. (2000). Europa, modernidad y eurocentrismo. En La colonialidad del saber: eurocentrismo y ciencias sociales. Perspectivas latinoamericanas. Buenos Aires, CLACSO.

Ferró, M. (1993). Cómo se cuenta la historia a los niños del mundo entero. México: FCE.

Gramsci, A. (1999). Cuadernos de la cárcel. Tomo V. México: Ediciones ERA.

Grinberg, S. (2010). Pedagogía y políticas sobre la vida en la sociedad de empresa: entre el gerenciamiento y lo abyecto. Relatos de racionalidad fragmentada. En Biopolíticas del Sur. Santiago: Editorial Universidad Arcis.

Iggers, G. (2012). La historiografía del siglo XX. Desde la objetividad científica al desafío posmoderno. Chile: Fondo de Cultura Económica.

Illanes, M. (1990). Ausente, señorita: el niño chileno, la escuela para pobres y el auxilio 1890/1990: (hacia una historia social del siglo XX en Chile). Santiago: JUNAEB.

Illanes, M. (2002). La batalla de la memoria. Ensayos históricos de nuestro siglo. Chile, 19002000. Chile: Editorial Planeta.

Illanes, M. (2008). Política educativa y profundización de la desigualdad en Chile. Estudios pedagógicos (Valdivia), 34(2), 207-226. Recuperado de https://scielo.conicyt.cl/scielo. php?pid=S0718-07052008000200013\&script=sci_arttext\&tlng=e

Marano, M. G. (2004). Michael Apple y Basil Bernstein: Teoría sociológica y regulación pedagógica. Dos discursos sobre la Educación y el Poder. Serie Pedagógica, 4(5), 265303. Recuperado de http://www.fuentesmemoria.fahce.unlp.edu.ar/art_revistas/ pr.400/pr.400.pdf

Marimán, P., Caniuqueo, S., Millalén, J., y Levil R. (2006). ¡Escucha, winka! Cuatro ensayos de Historia Nacional Mapuche y un epílogo sobre el futuro. Santiago: LOM.

Monsálvez, D. (2012). La dictadura militar de Augusto Pinochet como Nueva Historia Política: perspectiva historiográfica y algunos temas para su indagación. Revista Austral de Ciencias Sociales, 23, 61-82.

Pinto, J. (2003). La formación del Estado y la nación, y el pueblo mapuche. Santiago: DIBAM.

Pinto, J., \& Valdivia, V. (2009). ¿Chilenos todos? La construcción social de la nación (18101840). Santiago: LOM. 
Silvia Rivera Cusicanqui. (2010). Ch'ixinakax utxiwa: una reflexión sobre prácticas y discursos descolonizadores Tinta Limón, Buenos Aires.

Rubio, G. (2013). Memoria, politica y pedagogía. Los caminos hacia la enseñanza del pasado reciente en Chile. Santiago: LOM.

Ruz-Fuenzalida, C. (2019). Construcción y trayectoria del currículum en Chile: una perspectiva desde las nuevas bases curriculares para tercer y cuarto año de enseñanza media. Revista Saberes Educativos, 4, 22-36.

Sandoval, P. (comp.). (2010). Repensando la subalternidad. Miradas críticas desde/sobre América Latina. Lima: Instituto de Estudios Peruanos.

Scott, J. (2008). Género e Historia. México: FCE.

Spivak, G. (2003). ¿Puede hablar el subalterno? Revista Colombiana de Antropología, 39, 297-362.

Vázquez, M. G. (2015). La calidad de la educación: Reformas educativas y control social en América Latina. Latinoamérica. Revista de Estudios Latinoamericanos, 60, 93-124.

Vilar, P. (1999). Iniciación al vocabulario del análisis histórico. Barcelona: Crítica.

\section{FUENTES PRIMARIAS}

Aviso s/n. Ministerio de Educación, Chile, 18 de marzo de 2014. Recuperado de https://www. bcn.cl/leychile/consulta/vinculaciones/modificacion?idNorma=1059966\&fechaVigenc ia $=2015-01-01 \&$ clase_vinculacion=MODIFICACION

Decreto No 254. Ministerio de Educación, Chile, 26 de junio de 2009. Recuperado de https:// www.bcn.cl/leychile/navegar?idNorma $=1005222$

Decreto $\mathrm{N}^{0}$ 614. Ministerio de Educación, Chile, 24 de diciembre de 2013. Recuperado de https://www.bcn.cl/leychile/navegar?idNorma=1059966

Decreto $\mathrm{N}^{0}$ 369. Ministerio de Educación, Chile, 1 de septiembre de 2015. Recuperado de https://media.mineduc.cl/wp-content/uploads/sites/28/2017/07/Decreto-Ley-no 369-2015-Bases-Curriculares-7º-básico-a-2º-medio.pdf

Decreto $\mathrm{N}^{\circ}$ 193. Ministerio de Educación, Chile, 17 de junio de 2019. Recuperado de https:// www.bcn.cl/leychile/navegar?idNorma $=1136078$

Decreto Exento No 645. Ministerio de Educación, Chile, 16 de diciembre de 2009. Recuperado de https://www.bcn.cl/leychile/navegar?idNorma=1024514

Decreto con Fuerza de Ley No 2. Ministerio de Educación, Chile,16 de diciembre de 2009. Recuperado de https://www.bcn.cl/leychile/navegar?idNorma=1014974

Ministerio de Educación, Objetivos Fundamentales y Contenidos Mínimos Obligatorios de la Educación Básica y Media, Actualización 2009 y Bases Curriculares $7^{\circ}$ básico a $2^{\circ}$ medio. Ministerio de Educación, Historia, Geografía y Ciencias Sociales: Orientaciones y Guiones didácticos para docentes de $1^{\circ}$ y $2^{\circ}$ año de Educación Media, Santiago de Chile, marzo de 2015.

Ministerio de Educación, Orientaciones para la elaboración del Plan de Formación Ciudadana, Santiago de Chile, mayo de 2016.

Ministerio de Educación, Texto del Estudiante $1^{\circ}$ Medio, Historia, geografía y ciencias sociales, Aguilar Chilena de Ediciones, 2014. 
P. Arcos et al.

Ministerio de Educación, Texto del Estudiante $1^{\circ}$ Medio, Historia, geografía y ciencias sociales, Editorial Santillana, 2017.

Ministerio de Educación, Texto del Estudiante $2^{\circ}$ Medio, Historia, geografía y ciencias sociales, Editorial SM, edición 2013.

Ministerio de Educación, Texto del Estudiante $2^{\circ}$ Medio, Historia, geografía y ciencias sociales, Editorial Santillana, edición 2017.

Resolución Exenta No 0004. Consejo Nacional de Educación, República de Chile, 6 de enero de 2017. Recuperado de https://www.cned.cl/sites/default/files/acuerdos/ Res_2017_0004.pdf

\section{PRENSA DIGITAL}

Bustamante, R. (9 de febrero de 2011). "Lucha por tierras en Isla de Pascua”. BBC Mundo. Recuperado de https://www.bbc.com/mundo/noticias/2011/02/110209_0208_isla_ de_pascua_ao

Colegio de Profesores pedirá renuncia de encargada de currículum. (6 de enero de 2012). Cooperativa. Recuperado de https://www.cooperativa.cl/noticias/pais/ educacion/proyectos/colegio-de-profesores-pedira-renuncia-de-encargada-decurriculum-y/2012-01-06/161859.html

Carmona, A. (17 de enero de 2012). "El conflictivo historial de la unidad de currículum del MINEDUC”. El Mostrador. Recuperado de https://www.elmostrador.cl/ noticias/pais/2012/01/17/el-conflictivo-historial-de-la-unidad-de-curriculum-delMINEDUC/

Castillo, J. (15 de julio de 2019). “Colegio de Profesores realizó una presentación ante Contraloría por la reforma curricular”. ADN Radio Chile. Recuperado de https://www. adnradio.cl/nacional/2019/07/15/colegio-de-profesores-realizo-una-presentacionante-la-contraloria-por-la-reforma-curricular-3927486.html

Freixas, M. (21 de febrero de 2018). “Quién está detrás del Consejo Nacional de Educación, el organismo que quiere limitar el ramo de Filosofía”. El Desconcierto. Recuperado de https://www.eldesconcierto.cl/2018/02/21/quien-esta-detras-del-consejo-nacionalde-educacion-el-organismo-que-quiere-limitar-el-ramo-de-filosofia/

Foppiano, Gabriel (3 de junio de 2019) "El Consejo Nacional de Educación y la impronta antidemocrática del currículum escolar”. El quinto poder. Recuperado de https:// www.elquintopoder.cl/educacion/el-consejo-nacional-de-educacion-y-la-improntaantidemocratica-del-curriculum-escolar/

Saéz, I. (16 de febrero de 2018). "Dónde están los textos escolares”. El Mostrador. Recuperado de https://www.elmostrador.cl/noticias/opinion/2018/02/16/donde-estan-los-textosescolares-del-MINEDUC/

“Ministro Lavín se defiende de críticas por reducción de horas de Historia”. (18 de noviembre de 2010). El Mercurio Online (EMOL). Recuperado de https://www.emol.com/noticias/ nacional/2010/11/18/447983/ministro-lavin-se-defiende-de-criticas-por-reduccionde-horas-de-historia.html 
"Profesores acusan que reducción de horas de historia es una 'medida política". (25 de noviembre de 2010). La Tercera. Recuperado de https://www.latercera.com/noticia/ profesores-acusan-que-reduccion-de-horas-de-historia-es-una-medida-politica/

Ulloa, G. (5 de enero de 2012). "Coordinadora de MINEDUC asegura que concepto régimen militar en textos escolares enseña a pensar", BioBío Chile. Recuperado de https://www. biobiochile.cl/noticias/2012/01/05/coordinadora-de-MINEDUC-asegura-que-conceptoregimen-militar-en-textos-escolares-ensena-a-pensar.shtml 